\title{
O(s) Prémio(s) da Crítica 2006 Compromisso e tributo
}

\author{
Maria Helena Serôdio
}

O lugar e o tempo, como o teatro bem demonstra, são coordenadas imprescindiveis para que alguma coisa aconteça envolvendo actores e público. Mas, para lá dessa evidência, é forçoso reconhecer como o teatro vai invocando muitos ausentes que, na assombração do espectáculo e da sala, vão comparecendo e neles vão deixando a sua marca: autores, criadores, técnicos, memórias do passado, que, podendo não estar ali em corpo, por lá deixaram, muitas vezes, a energia, a invenção, o desafio e o prazer.

Para que a sessão da entrega do(s) Prémio(s) relativo(s) a 2006 ocorresse, a Associação Portuguesa de Críticos de Teatro contou com a gentil disponibilidade de Jorge Salavisa e toda a sua dinâmica e competente equipa do São Luiz Teatro Municipal, a quem muito agradecemos. Mas contou também com a atenção mobilizadora, que publicamente reconhecemos, do Pelouro da Cultura da Câmara Municipal de Lisboa, nas pessoas do Sr. Vereador, Dr. José Amaral

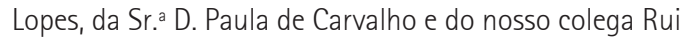
Cintra.

0 agradecimento maior, todavia, vai para os artistas que o júri da Associação de Críticos distinguiu, como indica o seu regulamento do Prémio, por se reconhecer, nos seus trabalhos em 2006, uma "invulgar contribuição para o panorama artístico nacional". E, com satisfação, acrescentamos ainda nesta invocação o público que generosamente compareceu à cerimónia de entrega e a quem prestamos a nossa merecida vénia.

0 júri foi constituido por Ana Pais, João Carneiro, Jorge Louraço Figueira, Maria Helena Serôdio e Rui Pina Coelho e o Prémio da Crítica, relativo ao ano de 2006, foi atribuído ex-aequo a Maria João Luís e a João Lagarto, pelas suas interpretações, respectivamente, no espectáculo Stabat Mater, dos Artistas Unidos, e Começar a acabar, uma co-produção dos Crónicos Associação Cultural, ACE - Teatro do Bolhão e Teatro Nacional D. Maria II.

0 mesmo júri decidiu ainda atribuir três Menções Especiais, respectivamente, a João Mota, pela concepção cénica de Todos os que caem, do Teatro A Comuna, a Patrícia Portela, pela dramaturgia da Trilogia Flatland, e a Fernando Mota, pela música e espaço sonoro do espectáculo Por detrás dos montes, do Teatro Meridional (em co-produção com o Teatro Nacional S. João e Teatro Municipal de Bragança).

E é por duas razões maiores que os Críticos - aqueles que estão reunidos nesta Associação - consideram importante este seu comprometimento com o teatro que se vai fazendo: para que publicamente dêem testemunho da qualidade de algumas criações (explicitando razões e mobilizando critérios) e para que, desta maneira, se criem condições acrescidas para que os meios de comunicação - desejavelmente - concedam mais atenção e espaço às coisas do teatro. Sonhamos, como é natural, que os alinhamentos dos telejornais se precipitem, e entre si rivalizem, para abrirem com o destaque aos premiados, à obra em si, à carreira de cada um dos artistas, enfim, àquilo que pensamos justificar a informação certa e o tributo devido ao teatro. Falei em sonho, mas acredito na sua possivel concretização um dia.

Reconhecemos que não haverá condições ideais para que o recenseamento do teatro a fazer no plano nacional seja exaustivo, por se tratar de uma realidade atomizada, de passagem por vezes fugidia pelos palcos, e por dela não ser possivel recolher "exemplares" como farão os júris da literatura, da música ou do cinema. Mas nisso a crítica compartilha o fulgor e o risco da própria criação teatral e, de algum modo, declara que não quer eximir-se a esse compromisso e a esse risco.

De resto, embora Bernard Dort tenha ido buscar a Dante a imagem do "par infernal" para falar da relação entre criador e crítico - na convicção de que se trata de um indeclinável companheirismo sempre à beira da irreconciliação - a verdade é que esse prestigiado crítico fala dessa relação e exerce-a (ou exerceu-a, mais correctamente) na convicção funda de que ela será vital e mutuamente implicando-se criação e crítica. Que se compreenda que essa proximidade suscite alguma exasperação e eventuais desentendimentos não significa, em definitivo, que isso legitime quaisquer atitudes de ameaça ou coação física, o que esta Direcção da APCT naturalmente estará sempre pronta a condenar. Por outro lado, e comprovando, de algum modo, a especularidade destes dois campos, também não podemos deixar de lamentar profundamente que no próprio terreno da crítica, por vezes, se insinuem intrigas e alimentem mentiras, confundindo debate com maledicência. Porém, é evidente que estas são as excepções - pela negativa - e sabemos de ciência certa que, felizmente, há mais mundo.

Mas a cerimónia que se celebrou no belíssimo Jardim de Inverno do Teatro São Luiz, no passado dia 26 de Março, foi, de facto, um momento de celebração e de alegria, demonstrando que a crítica também sabe fazer convergir esforços, aplaudir o que considera de qualidade,

comprometer-se com o real, e participar publicamente no tributo que merecem os nossos criadores. E para justificar as suas decisões aqui ficam as razões do júri que, veiculando ideias do colectivo, se desdobraram nas cinco vozes/escritas dos seus membros. 
Jorge Louraço Figueira,

Maria Helena Serôdio,

João Carneiro

e Rui Pina Coelho.

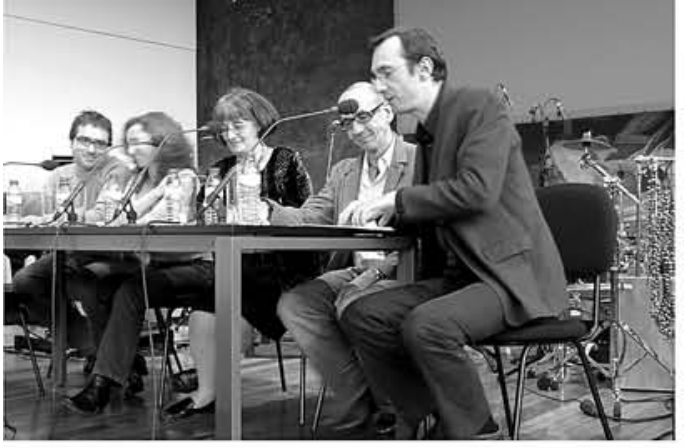

Maria João Luis.

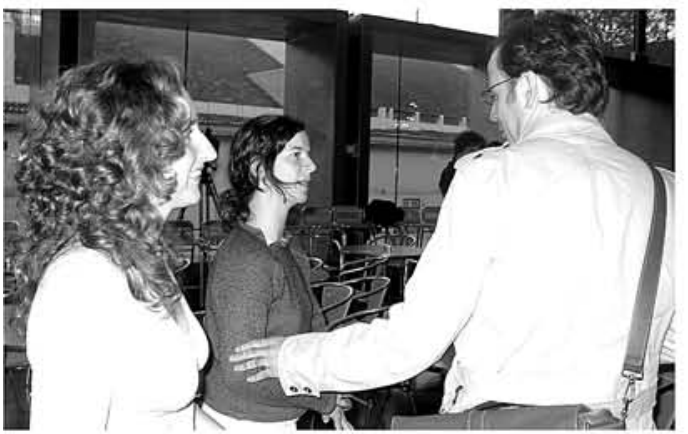

Carla Maciel

(em representação de

Fernando Mota).

Jã̃o Lagarto.

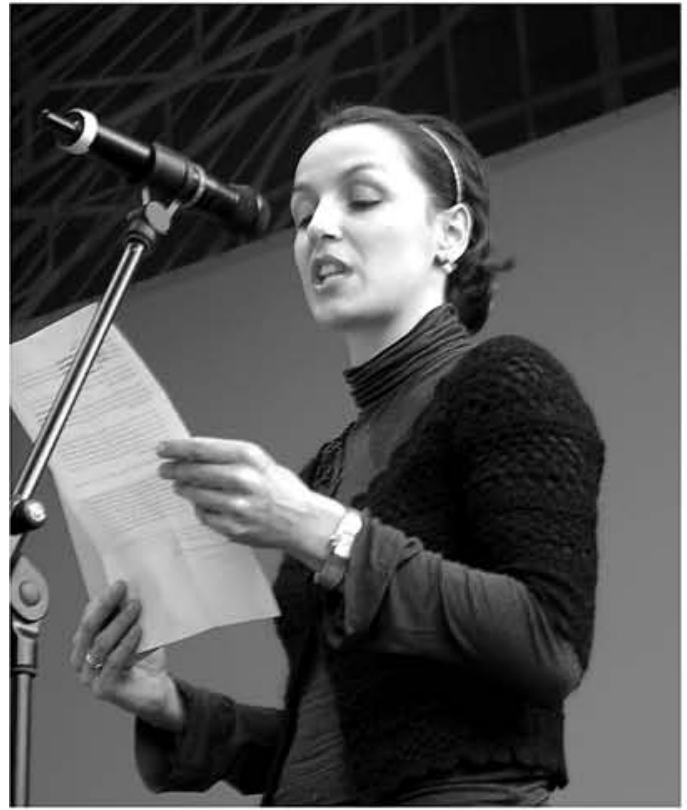

Patricia Portela.

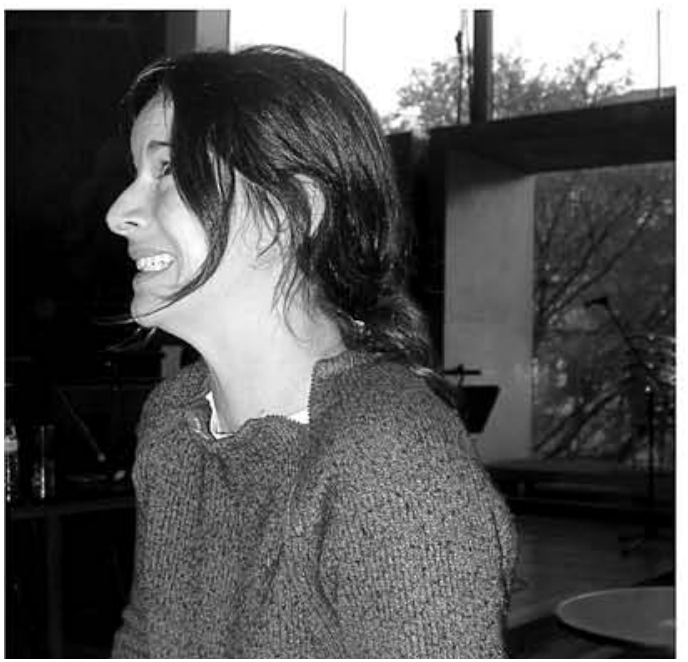

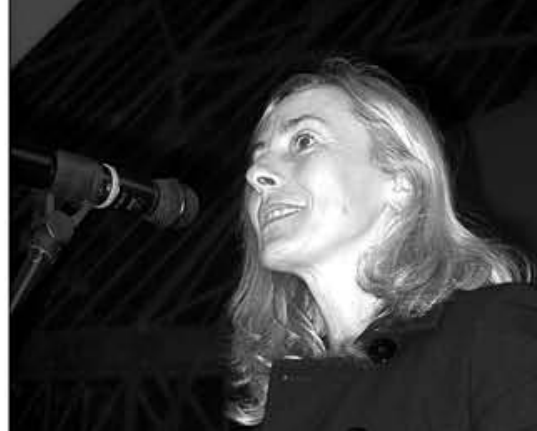
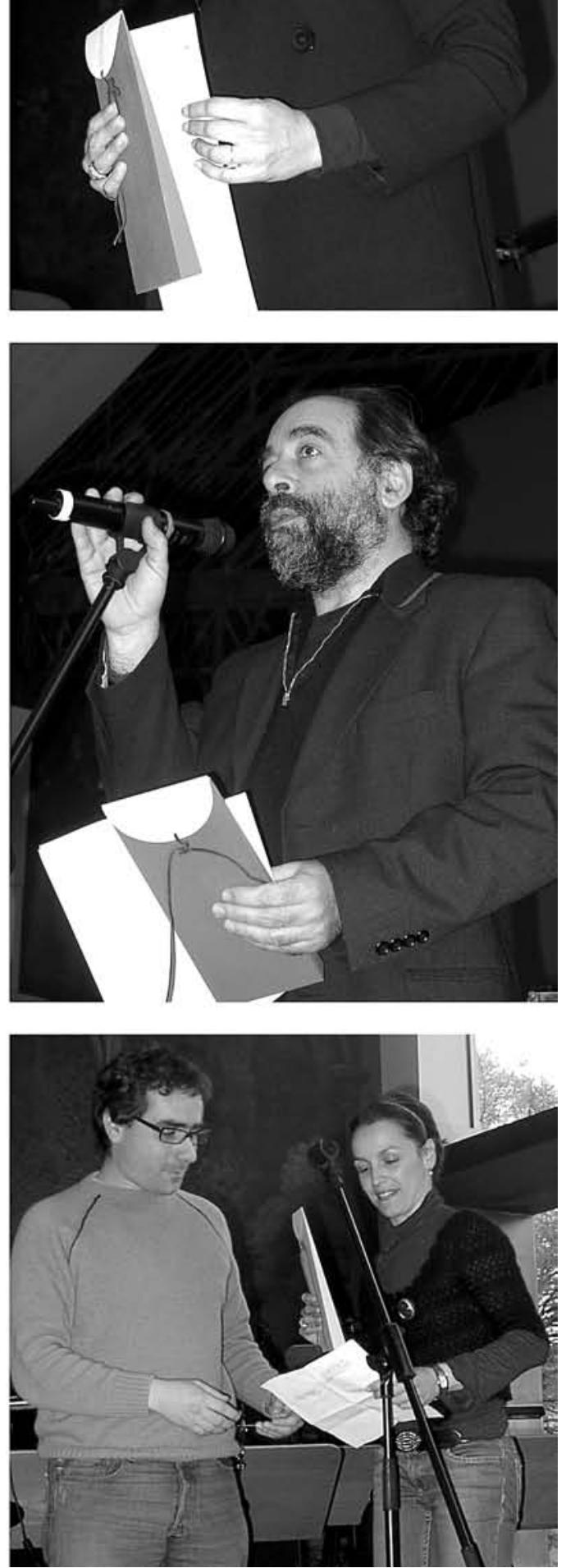